\title{
Antioxidants used in Restorative Dentistry
}

\author{
Laden Güleç Alagöz [1), Özgü illkcan Karadağlıoğlu, Nuran Ulusoy [i] \\ Department of Restorative Dentistry, Near East University Faculty of Dentistry, Nicosia, Cyprus
}

ORCID IDs of the authors: L.G.A. 0000-0002-3440-3102; N.U. 0000-000I-6289-3105.

Cite this article as: Güleç Alagöz L. Karadağlıoğlu i, Ulusoy N. Antioxidants used in Restorative Dentistry. Cyprus J Med Sci 2019; 4(2): $|4|-5$.

\begin{abstract}
In recent years, antioxidants have been successfully used in dentistry because of their beneficial effects on human health. The most important effect of antioxidants known is to neutralize the harmful effects of free radicals. Free radicals can cause destruction of cell membranes and DNA, DNA mutations, lipid peroxidation, and other diseases. Although not routinely used, the use of antioxidants continues to expand worldwide, and studies are conducted to determine the effective use of these products. In the field of restorative dentistry, antioxidants are used for bonding procedures after bleaching, remineralization, hypersensitivity, and pulp capping. This review highlights the use and clinical significance of antioxidant therapy in these treatment modalities of restorative dentistry.
\end{abstract}

Keywords: Antioxidant, restorative dentistry, dental bleaching, remineralization, pulp capping, dentin hypersensitivity

\section{INTRODUCTION}

The term antioxidant is used for molecules that reduce the damaging capacity of free radicals using their scavenging property. They are stable enough for donating an electron to a rampaging free radical and neutralizing it (I). Free radical species were defined by Halliwell et al. (2) as "any species capable of independent existence that contains one or more unpaired electrons." They can be in the form of reactive oxygen species (ROS) or reactive nitrogen species. ROS can lead to tissue damage by different mechanisms, such as DNA damage, lipid peroxidation, protein damage, and oxidation of important enzymes (3).

Antioxidants that are helpful in inhibiting the negative effects of ROS can include the following:

I. The "scavenging" or "chain-breaking" antioxidants, such as alpha tocopherol (vitamin E), ascorbic acid (vitamin C), beta carotene (vitamin A), urate, and bilirubin (4). These antioxidants scavenge the active radicals to suppress chain initiation and/or break the chain propagation reactions (I).

2. Thiol-containing antioxidants named as "preventative antioxidants," such as albumin, transferrin, lactoferrin, ceruloplasmin, haptoglobin, and ascorbic acid. These are large proteins by nature (4). These antioxidants also suppress free radical formation by reducing hydroperoxides and hydrogen peroxides $\left(\mathrm{H}_{2} \mathrm{O}_{2}\right)$ to alcohol and water without forming free radicals, respectively $(\mathrm{I})$.

3. Enzyme antioxidants that function by catalyzing the oxidation of other molecules, such as superoxide dismutase, catalase, and glutathione systems $(\mathrm{l}, 4)$.

Antioxidants were used in studies related to industrial processes in the late 19th and 20th centuries. In the field of biology, the first research focused on the use of antioxidants in preventing the oxidation of unsaturated fats (I).

Antioxidants are also widely used in dentistry. Eugenol with its scavenging, preventing effect and presence of enzyme activator for antioxidant action has been used effectively for toothache. Epigallocatechin-3-gallate in green tea reduces the risk of dental caries and plaque formation with its scavenging effect (4). 
In this review, the effects of antioxidants in the treatment methods of restorative dentistry including bonding procedures after bleaching, remineralization, hypersensitivity, and pulp capping were compiled.

\section{Bond strength after bleaching}

Dental bleaching is a cosmetic procedure that is often requested in clinical practice. The bleaching procedure can be classified into two groups as vital bleaching and nonvital bleaching (5).

Vital tooth bleaching techniques are further divided into two groups as home and office bleaching done with carbamide peroxide and $\mathrm{H}_{2} \mathrm{O}_{2}$, respectively (6). Bleaching agents can cause different side effects, such as pulpal sensitivity, microleakage in restorations, external root resorption, and changes in the composition of tooth structure (7-9). Vital dental bleaching agents contain $\mathrm{H}_{2} \mathrm{O}_{2}$ or carbamide peroxide ranging from $3 \%$ to $40 \%$ (5).

Lasers and lights are used to initiate the dental bleaching procedure under a photochemical reaction. As a result of this chemical interaction, an increase in the release of hydrogen released from $\mathrm{H}_{2} \mathrm{O}_{2}$ is observed (10). $\mathrm{H}_{2} \mathrm{O}_{2}$ is an agent that decomposes and creates unstable free radicals, such as perhydroxyl radicals, hydroxyl radicals, superoxide anions, and perhydroxyl anions, when it diffuses into the tooth, thus causing oxidation (II).

Many studies have shown that carbamide peroxide and $\mathrm{H}_{2} \mathrm{O}_{2}$ can negatively affect the bonding strength of the composite to the tooth structure (12-14).

Some methods, such as delayed bonding (wait time, $24 \mathrm{~h}$ to 3 weeks), removal of the enamel, the use of acetone-based adhesives, alcohol application on the tooth surface, and the use of antioxidants, are proposed to counteract the decreasing bond strength after bleaching (15-17).

Nowadays, some studies have proven that the use of antioxidants, such as sodium ascorbate, alpha tocopherol, grape seed, and proanthocyanidin, can eliminate the harmful effects caused by free radicals after dental bleaching and can increase the bond strength of composite resins $(18,19)$.

Aloe vera, pomegranate peel, grape seed extract, green tea, and sodium ascorbate were used in a study to evaluate the effects of different antioxidants on shear bond strength to home-bleached enamel. The untreated group was determined as the control group. No significant differences were observed between the shear bond strength of the control group and the experimental groups treated with different antioxidants (20).

It was shown in a study comparing the effectiveness of $10 \%$ sodium ascorbate and $5 \%$ proanthocyanidin agents on the bond strength after bleaching that the use of antioxidants before bonding on bleached surfaces reverses the harmful effect of bleaching agents and increases bond strength (2l).

The benefits of three herbal antioxidants, such as 5\% grape seed extract, $5 \%$ pine bark extract, and $5 \%$ pomegranate peel extract, on the recovery of reduced bond strength were investigated. As a result, it was found out that the use of antioxidants, especially $5 \%$ pine bark extract application after bleaching to- tally neutralizes the deleterious effects of bleaching on enamel surface and increases the SBS significantly (22).

An in vitro study compared the effects of $35 \%$ sodium ascorbate application as an antioxidant and I-week delayed bonding procedure on microtensile bond strength after bleaching. According to the results, 35\% sodium ascorbate application showed similar bonding strength to I-week delayed bonding procedure. In this study, both delayed bonding and immediate bonding procedures were found as time-saving applications that restored the bond strength similar to the original bond strength (23).

Alpha tocopherol, 10\% ascorbic acid, and hesperidin were used for evaluating the effects of antioxidants on microshear bond strength after chemical and laser bleaching. Hesperidin and ascorbic acid applications showed no significant differences compared with the control group that exhibited the highest microshear bond strength value. Alpha tocopherol showed the lowest microshear bond values. The results of the study showed that immediate bonding procedures could be applied after laser-assisted bleaching without the need for antioxidant application since laser-assisted bleaching did not induce surface morphological changes (24).

An in vitro study examined the shear bond strengths of composite resins to bleached enamel using 10\% sodium ascorbate, 10\% alpha tocopherol, 10\% grape seed extract, and 10\% guava seed extract as antioxidants. The results showed that guava seed extract was the most effective antioxidant increasing the bond strength. With the use of these antioxidants, the bonding strengths of the bleached enamel were effectively increased (25).

Dikmen et al. (26) investigated the effects of some antioxidants, such as proanthocyanidin, Accel, and noni fruit juice, on the microtensile bond strength of a single etching adhesive system on dentin treated by sodium hypochlorite $(\mathrm{NaOCl})$. No significant differences were found among the antioxidant-treated groups. The $\mathrm{NaOCl}$ group showed lower microtensile bond strength than the other groups.

Nonvital bleaching includes several techniques, such as walking bleaching or nonvital power bleaching. The most commonly used procedure is walking bleaching. The mixture of sodium perborate and water is placed in a pulp chamber, and this application is maintained until the desired color is achieved (5). Antioxidants can be used, such as vital bleaching technique, for immediate restoration. According to an in vitro study, sodium ascorbate was applied as an antioxidant after nonvital bleaching, the shear bond strength of the composite to the bleached dentin was evaluated, and the effects were compared with calcium hydroxide, $\mathrm{Ca}(\mathrm{OH})_{2}$, a buffering agent. The results of the study showed that sodium ascorbate showed a significant increase in the bond shear strength of composite, whereas $\mathrm{Ca}(\mathrm{OH})$, showed failure (27).

Aslan et al. (28) compared the effect of immediate cemetation with delayed cemetation-on the bond strength of fiber posts after intracoronal bleaching with 35\% carbamide peroxide. Researchers divided the experimental groups into 5 as; no bleaching, immediate cementation, immediate cemetation after 
antioxidant application (Sodium ascorbate), 14-days delayed cemetation and 14 days delayed cemetation after sodium ascorbate application. The 14-day delayed bonding was reported to be more effective than the use of sodium ascorbate application.

\section{Remineralization}

In 2010, remineralization was defined by Cochrane et al. (29) as "the process whereby calcium and phosphate ions are supplied from a source external to the tooth to promote ion deposition into crystal voids in demineralized enamel to produce net mineral gain."

Proanthocyanidins are found in grape seeds and grape seed extracts. Silva et al. (30) compared the remineralization effect of grape seed extract and fluoride under cariogenic challenge on enamel and dentin. The samples that were treated with grape seed extract and fluoride showed statistically higher remineralization than the untreated group (30).

Hesperidin is a citrus flavonoid antioxidant. Hiraishi et al. (3I) compared the effect of hesperidin on the remineralization of dentin lesions with chlorhexidine. Their study showed that hesperidin enhances remineralization by protecting the collagen structure (3I).

According to a study in 2017, researchers used two antioxidants after bleaching and observed their effects on enamel structure and hydroxyapatite crystal growth. In the study, catalase and sodium ascorbate were used as antioxidants, and the test groups were examined after $72 \mathrm{~h}$. The results showed that using antioxidant after bleaching can increase the remineralization capability of saliva, but the topographical properties do not reverse to the initial form (32).

Catalase is an antioxidant that provides remineralization in the fluoride-mediated enamel microstructure, removes free radicals effectively, and affects enamel stiffness. Thakur et al. (33) aimed to neutralize the free acids by applying catalase to teeth treated with $37 \%$ hydrogen peroxide as whitening treatment and to restore the surface hardness by topical fluoride application. The surface hardness of whitened enamel was found to significantly increase with catalase and fluoride applications.

\section{Dentin hypersensitivity}

Dentin hypersensitivity is a short and sharp pain arising from exposed dentin in response to a thermal, evaporative, tactile, osmotic, or chemical stimulus and cannot be associated with any other form of dental pathology or defect. The most widely accepted theory behind the mechanism of dentin hypersensitivity is the hydrodynamic theory often attributed to Brannstrom (34-36). According to this theory, the abrupt movement of fluid within the dentinal tubules causes an outward flow of fluid from the pulp to open dentin surface, causing hypersensitivity (34). The treatment modalities of hypersensitivity include occluding the dentinal tubules or impeding or diminishing neural transmission $(34,35)$. For this purpose, several strategies, such as lasers, iontophoresis, dentin sealers, and soft tissue grafting, are used. The use of toothpastes is widely preferred in delivering the desensitizing agents (37). Desensitizing agents, such as potassium, fluoride, hydroxyapatite, copal varnishes, and $\mathrm{Ca}(\mathrm{OH})_{2}$, or dentin bonding agents are used $(34,38)$. There has been a growing interest in the use of natural products and antioxidants for the treatment of dentin hypersensitivity $(37,38)$. According to the results of a study, a dentifrice containing antioxidants, such as ferulic acid, silymarin, and phloretin, in addition to sodium monofluorophosphate, nano-hydroxyapatite, and potassium nitrate, reduced dentinal hypersensitivity in a 2-day to 2 -week period (34).

Propolis, a bee product, has been a striking natural agent for the treatment of dentin hypersensitivity (38). Sankari et al. (39) stated that propolis occludes dentinal tubules and reduces dentinal hypersensitivity of periodontally involved teeth. Purra et al. (38) compared the desensitizing effect of propolis with $5 \%$ potassium nitrate and distilled water. Their results showed that propolis is the most effective desensitizing agent in the intermediate relief of sensitivity.

Madhawan et al. (36) compared the clinical efficiency of propolis with sodium fluoride, casein phosphoprotein-amorphous calcium phosphate fluoride, and distilled water and found that propolis is the most rapid agent in treating dentinal hypersensitivity. Another study pointed out that propolis showed the most rapid decrease of dentin hypersensitivity compared with hydroxyapatite, sodium fluoride, and potassium nitrate. The authors interpreted that the anti-inflammatory action of propolis stimulates reparative dentin formation that is able to reduce dentin permeability (40)

\section{Pulp capping}

When dental pulp is exposed either traumatically or because of caries, direct pulp capping technique is used for protecting pulpal health and function, allowing the patients to retain their teeth longer and at lower costs than root canal treatment, which is an alternative invasive technique (4I). For this purpose, a wide range of materials have been used $(42,43)$. These materials should control infection, prevent microleakage, promote hard tissue formation, and should be handled easily (42).

Some of the materials used for direct pulp capping are zinc oxide eugenol (ZOE), glass ionomer cement or resin-modified glass ionomer cement, adhesive systems, $\mathrm{Ca}(\mathrm{OH})_{2}$, and mineral trioxide aggregate (MTA). Eugenol has been used for many years in dentistry as liners, bases, cements, or temporary restorations. However, capping is questionable. Since the cytotoxicity of ZOE is high, controversy exists for its use in direct pulp capping therapies (44).

$\mathrm{Ca}(\mathrm{OH})_{2}$ has been accepted as the gold standard in vital pulp therapies (4I). When it is applied to the exposed pulp tissue, it induces hard tissue formation that is an important advantage in vital pulp therapies (42). However, high solubility in oral fluids, lack of adhesion, and degradation after acid etching are some of the undesirable effects of this material (43). Additionally, the high $\mathrm{pH}$ (12.5) causes the destruction of cell membranes and protein structures. The reparative dentin formed by $\mathrm{Ca}(\mathrm{OH})$, results in a porous and incomplete barrier structure, and the formation of extensive dentin causes the obliteration of pulp chamber (42, 43).

As stated previously, the high $\mathrm{pH}$ value also made $\mathrm{Ca}(\mathrm{OH})_{2}$ a toxic material and prone to dissolve soft tissue that causes 
chronic inflammation and cell necrosis. Al-Shaher et al. (45) found that propolis, an antioxidant agent, has superior properties than $\mathrm{Ca}(\mathrm{OH})_{2}$ and does not produce pulpal inflammation, necrosis, and infection while inducing tubular and high qualified dentin production.

Mineral trioxide aggregate is a pulp capping agent that consists of calcium oxide, tricalcium silicate, dicalcium silicate, tricalcium aluminate, and bismuth oxide. Although $\mathrm{Ca}(\mathrm{OH})_{2}$ and MTA have many similarities, such as antibacterial property, radiopacity, or biocompatibility, MTA has some advantages, such as containing iron or sealing ability (44).

The results of a study that compared the effects of ProRoot MTA (Dentsply Caulk Milford, DE, USA) (MTA material), Dycal (Dentsply Caulk Milford) $\left(\mathrm{Ca}(\mathrm{OH})_{2}\right.$ material), and propolis showed that the response of dental pulps to propolis was comparable to $\mathrm{Ca}(\mathrm{OH})_{2}$ and MTA (43).

Ahangari et al. (42) investigated the effect of propolis as an alternative material to $\mathrm{Ca}(\mathrm{OH})_{2}$ on dentin regeneration and on the potential role of dental pulp stem cells. They reported that although more stem cells were found in the $\mathrm{Ca}(\mathrm{OH})_{2}$ control group at each time point, the propolis group showed superior properties over $\mathrm{Ca}(\mathrm{OH})_{2}$ with respect to the prevention of the formation of inflammation, infection, and necrosis and inducing the formation of higher quality tubular dentin. The anti-inflammatory property of propolis aids to inhibit the synthesis of prostaglandins and helps the immune system by promoting phagocytic activity, stimulating cellular immunity, and increasing the healing effects on epithelial tissue. Additionally, the elements of propolis, such as iron and zinc, are effective in the synthesis of collagen, and flavonoids regulate the immune system response $(43,46)$. According to the results of a study, propolis flavonoids, as direct pulp capping agents, can stimulate reparative dentin and may delay the formation of pulp inflammation (46). Parolia et al. (43) reported that the response of dental pulps to propolis as a pulp capping agent is comparable to that of ProRoot MTA (Dentsply Caulk Milford) and Dycal (Dentsply Caulk Milford). Sabir et al. (46) reported that propolis delays pulpal inflammation and stimulates reparative dentin formation.

Glass ionomer cements/resin glass ionomer cements and adhesive systems are cytotoxic when they are placed directly on the pulp tissue. These two agents showed chronic inflammation when used as direct pulp capping agents $(44,47)$. N-acetylcysteine (NAC) showed significant antioxidant effect by inhibiting glutathione depletion (48). Goldberg et al. (48) reported that NAC induces reparative dentin formation in a rat molar model. The effect of NAC in reducing cytotoxicity and in inducing mineralized tissue conductivity with resin-modified glass ionomer cements was examined. NAC detoxifies and functionalizes resin-modified glass ionomer cements by detoxification and antioxidant cell proliferation (49).

Catalase, as an oxidoreductase of $\mathrm{H}_{2} \mathrm{O}_{2^{\prime}}$ has been used as one of the enzymatic defense mechanisms of the body against toxic oxygen species or reactive oxygen intermediates. Alaçam et al. (50) reported that perforated dog teeth treated with the topical application of catalase antioxidant enzyme showed better healing in the 90-day period than the teeth treated without catalase.

\section{CONCLUSION}

Although there are studies showing the benefits of antioxidant use in restorative dentistry including bonding procedures after bleaching, remineralization, hypersensitivity, and pulp capping, studies must be conducted on reducing the risk of dental caries and plaque formation to determine the most appropriate material and methods for the exact regeneration of dentin-pulp complex and to reduce the undesirable effects caused by dentin hypersensitivity. Most of the studies proved that the use of antioxidant agents improves the bond strength after bleaching. As a result, the use of antioxidants can open a new possible treatment modality for restorative procedures to prevent the negative effects of ROS.

Peer-review: Externally peer-reviewed.

Author contributions: Concept - L.G., Ö.I.K.;Design - L.G.A., Ö.I.K.; Supervision - N.U., L.G.A.; Resource - L.G.A., Ö.I.K.; Materials - L.G.A., Ö.I.K.; Data Collection and/or Processing - L.G.A., Ö.I.K.; Analysis and/or Interpretation - L.G.A., N.U.; Literature Search - L.G.A., Ö.I.K.; Writing - L.G.A., Ö.I.K., N.U.; Critical Reviews - L.G.A., N.U.

Conflict of Interest: The authors have no conflicts of interest to declare.

Financial Disclosure: The authors declared that this study has received no financial support.

\section{REFERENCES}

I. Lobo V, Patil A, Phatak A, Chandra N. Free radicals, antioxidants and functional foods: Impact on human health. Pharmacogn Rev 2010; 4: II8-26. [CrossRef]

2. Halliwell B, Gutteridge JM, Cross CE. Free radicals, antioxidants, and human disease: where are we now? J Lab Clin Med 1992; 119: 598-620.

3. Chapple ILC. Reactive oxygen species and antioxidants in inflammatory diseases. J Clin Periodontol 1997; 24: 287-96. [CrossRef]

4. Carnelio S, Khan SA, Rodrigues G. Definite, probable or dubious: antioxidants trilogy in clinical dentistry. Br Dent J 2008; 204: 29-32. [CrossRef]

5. Alqahtani $M Q$. Tooth-bleaching procedures and their controversial effects: A literature review. Saudi Dent J 2014; 26: 33-46. [CrossRef]

6. Türkün $M$, Kaya $A D$. Effect of $10 \%$ sodium ascorbate on the shear bond strength of composite resin to bleached bovine enamel. J Oral Rehabil 2004; 31: II84-9I. [CrossRef]

7. Sharafeddin F, Varachehre MY. Evaluation of microleakage in composite restoration by using self-etch adhesive agents after using $35 \%$ carbamide peroxide bleaching gel. J Dent Isfahan Dent Sch 2008; 4: 67-74.

8. Sharafeddin F, Jamalipour GR. Effects of $35 \%$ carbamide peroxide gel on surface roughness and hardness of composite resins. J Dent (Tehran) 2010; 7: 6-12.

9. Khoroushi M, Saneie T. Post-bleaching application of an antioxidant on dentin bond strength of three dental adhesives. Dent Res J (Isfahan) 2012; 9: 46-53. [CrossRef]

10. Kashima-Tanaka M, Tsujimoto Y, Kawamoto K, Senda N, Ito K, Yamazaki M. Generation of free radicals and/or active oxygen by light or laser irradiation of hydrogen peroxide or sodium hypochlorite. J Endod 2003; 29: 141-3. [CrossRef]

II. Dahl JE, Pallesen U. Tooth bleaching--a critical review of the biological aspects. Crit Rev Oral Biol Med 2003; 14: 292-304. [CrossRef]

12. Dishman MV, Covey DA, Baughan LW. The effects of peroxide bleaching on composite to enamel bond strength. Dent Mater 1994; 10: 33-6. [CrossRef]

13. Cavalli $V$, Ries AF, Giannini M, Ambrosano GM. The effect of elapsed time following bleaching on enamel bond strength of resin composite. Oper Dent 2001; 26: 597-602. 
14. Cavalli V, Carvalho RMD, Giannini M. (2005). Influence of carbamide peroxide-based bleaching agents on the bond strength of resin-enamel/dentin interfaces. Braz Oral Res 2005; 19: 23-9. [CrossRef]

15. Lai SCN, Tay FR, Cheung GSP, Mak YF, Carvalho RM, Wei SHY, et al. Reversal of compromised bonding in bleached enamel. J Dent Res 2002; 81: 477-81. [CrossRef]

16. Kimyai $\mathrm{S}$, Valizadeh $\mathrm{H}$. The effect of hydrogel and solution of sodium ascorbate on bond strength in bleached enamel. Oper Dent 2006; 31: 496-9. [CrossRef]

17. Muraguchi K, Shigenobu S, Suzuki S, Tanaka T. Improvement of bonding to bleached bovine tooth surfaces by ascorbic acid treatment. Dent Mater J 2007; 26: 875-8I. [CrossRef]

18. Sasaki RT, Flório FM, Basting RT. Effect of $10 \%$ sodium ascorbate and $10 \% \alpha$-tocopherol in different formulations on the shear bond strength of enamel and dentin submitted to a home-use bleaching treatment. Oper Dent 2009; 34: 746-52. [CrossRef]

19. Epasinghe DJ, Yiu CKY, Burrow MF, Tay FR, King NM. Effect of proanthocyanidin incorporation into dental adhesive resin on resin-dentine bond strength. J Dent 2012; 40: 173-80. [CrossRef]

20. Sharafeddin F, Farshad F. The effect of aloe vera, pomegranate peel, grape seed extract, green tea, and sodium ascorbate as antioxidants on the shear bond strength of composite resin to homebleached enamel. J Dent (Shiraz) 2015; 16: 296-301.

21. Manoharan M, Shashibhushan KK, Poornima P, Naik SN, Patil D, Shruthi AS. Effect of newer antioxidants on the bond strength of composite on bleached enamel. J Indian Soc Pedod Prev Dent 2016; 34: 391-6. [CrossRef]

22. Mukka PK, Komineni NK, Pola S, Soujanya E, Karne AR, Nenavath B, et al. An in-vitro comparative study of shear bond strength of composite resin to bleached enamel using three herbal antioxidants. J Clin Diagn Res 2016; 10: ZC89-92. [CrossRef]

23. Ismail EH, Kilinc E, Hardigan PC, Rothrock JK, Thompson JY, Garcia-Godoy C. Effect of two-minute application of 35\% sodium ascorbate on composite bond strength following bleaching. J Contemp Dent Pract 2017; 18: 874-80. [CrossRef]

24. Sultan MS, Elkorashy ME. Influence of natural antioxidants on microshear bond strength to bleached enamel: chemical versus laser assisted bleaching. Egypt Dent J 2017; 63: 419- 27.

25. Gogia H, Taneja S, Kumar M, Soi S. Effect of different antioxidants on reversing compromised resin bond strength after enamel bleaching: An in vitro study. J Conserv Dent 2018; 21: 100-4.

26. Dikmen B, Gurbuz O, Ozsoy A, Eren MM, Cilingir A, Yucel T. Effect of different antioxidants on the microtensile bond strenght of an adhesive system to sodium hypochlorite-treated dentin. J Adhes Dent; 2015; 17: 499-504.

27. Feiz A, Khoroushi M, Gheisarifar M. Bond strength of composite resin to bleached dentin: effect of using antioxidant versus buffering agent. J Dent (Tehran) 20Il; 8: 60-6.

28. Aslan T, Üstün Y, Sağsen B, Șener I, Biricik E, Tatlı Ș. The effects of antioxidant application and time factor on fiber post bonding to root dentin after intracoronal bleaching. Int Dent Res 2018; 8: 22-7. [CrossRef]

29. Cochrane NJ, Cai F, Huq NL, Burrow MF, Reynolds EC. New approaches to enhanced remineralization. J Dent Res 2010; 89: II8797. [CrossRef]

30. Silva APPD, Gonçalves RS, Borges AFS, Bedran-Russo AK, Shinohara MS. Effectiveness of plant-derived proanthocyanidins on demineralization on enamel and dentin under artificial cariogenic challenge. J Appl Oral Sci 2015; 23: 302-9. [CrossRef]
31. Hiraishi N, Sono R, Islam MS, Otsuki M, Tagami J, Takatsuka T. Effect of hesperidin in vitro on root dentine collagen and demineralization. J Dent 20ll; 39: 39I-6. [CrossRef]

32. Bhusari CP, Sharma DS. Pattern of hydroxyapatite crystal growth on bleached enamel following the application of two antioxidants: an atomic force microscope study. J Clin Pediatr Dent 2017; 4I: 38-47. [CrossRef]

33. Thakur R, Shigli AL, Sharma D, Thakur G. Catalase and sodium fluoride mediated rehabilitation of enamel bleached with $37 \%$ hydrogen peroxide. J Indian Soc Pedod Prev Dent 2015; 33: 324-30. [CrossRef]

34. Low SB, Allen EP, Kontogiorgos ED. Reduction in dental hypersensitivity with nano-hydroxyapatite, potassium nitrate, sodium monoflurophosphate and antioxidants. Open Dent J 2015; 27: 92-7. [CrossRef]

35. Shiau HJ. Dentin hypersensitivity. J Evid Based Dent Pract 2012; 12: 220-8. [CrossRef]

36. Madhavan S, Nayak M, Shenoy A, Shetty R, Prasad K. Dentinal hypersensitivity: A comparative clinical evaluation of CPP-ACP F, sodium fluoride, propolis, and placebo. J Conserv Dent 2012; 15: 315-8 [CrossRef]

37. Kumar G, Jalaluddin M, Rout P, Mohanty R, Dileep CL. Emerging trends of herbal care in dentistry. J Clin Diagn Res 2013; 7: 1827-9.

38. Purra AR, Mushtaq M, Acharya SR, Saraswati V. A comparative evalvation of propolis and $5.0 \%$ potassium nitrate as a dentine desensitizer: A clinical study. J Indian Soc Periodontol 2014; I8: 466-7I. [CrossRef]

39. Sankari SL, Babu NA, Rani V, Priyadharsini C, Masthan KMK. Flavonoids-Clinical effects and applications in dentistry: A review. J Pharm Bioallied Sci 2014; 6: S26-9. [CrossRef]

40. Mehta P, Vimala N, Mandke L. An insight into dentin desentizing agents-In Vivo study. Indian J Dent Res 2013; 24: 57I-4. [CrossRef]

4l. Schwendicke F, Brouwer F, Schwendicke A, Paris S. Different materials for direct pulp capping: systematic review and meta-analysis and trial sequential analysis. Clin Oral Investing 2016; 20: II2I-32. [CrossRef]

42. Ahangari Z, Naseri M, Jalili M, Mansouri Y, Mashhadiabbas F, Torkaman A. Effect of propolis on dentin regeneration and the potential role of dental pulp stem cell in Guinea pigs. Cell J 2012; 13: 223-8.

43. Parolia A, Kundabala M, Rao NN, Acharya SR, Agrawal P, Mohan $M$, et al. A comparative histological analysis of human pulp following direct pulp capping with Propolis, mineral trioxide aggregate and Dycal. Aust Dent J 2010; 55: 59-64. [CrossRef]

44. Hilton TJ. Keys to clinical success with pulp capping: a review of the literature. Oper Dent 2009; 34: 615-25. [CrossRef]

45. Al-Shaher A, Wallace J, Agarwal S, Bretz W, Baugh D. Effect of propolis on human fibroblasts from the pulp and periodontal ligament. J Endod 2004; 30: 359-6I. [CrossRef]

46. Sabir A, Tabbu CR, Agustiono P, Sosroseno W. Histological analysis of rat dental pulp tissue capped with propolis. J Oral Sci 2005; 47: 135-8. [CrossRef]

47. Lopes do Nascimento A, Fontana U, Teixeira H, de SouzaCosta C. Biocompatibility of a resin-modified glass ionomer cement applied as pulp capping in human teeth. Am J Dent 2000; 13: 28-34.

48. Goldberg M, Six N, Decup F, Buch D, Soheili Majd E, Lasfargues JJ, et al. Application of bioactive molecules in pulp-capping situations. Adv Dent Res 2001; 15: 91-5. [CrossRef]

49. Minamikawa H, Yamada M, Iwasa F, Ueno T, Deyama Y, Suzuki K, et al. Amino acid derivative-mediated detoxification and functionalization of dual cure dental restorative material for dental pulp cell mineralization. Biomaterials 20I0; 31: 72I3-25. [CrossRef]

50. Alacam A, Tulunoglu Ö, Oygür T, Bilici S. Effects of topical Catalase application on dental pulp tissue: a histopathological evaluation. J Dent 2000; 28: 333-9. [CrossRef] 